\title{
Uji Mutu Ekstrak Daun Sirsak (Annona muricata Linn.) Yang Di Ekstraksi Secara Maserasi Dengan Pelarut Etanol 70\%
}

\section{Quality Test Of Extract Leaf Soursop (Annona muricata Linn.) The Extraction In Maseration With Ethanol Polluters 70\%}

\author{
Christica Ilsanna Surbakti ${ }^{1)}$ dan Nadiya ${ }^{2)}$ \\ Institut Kesehatan DeliHusada Delitua \\ Jalan Besar Delitua No. 77 Kab. Deli Serdang, Sumatera Utara \\ Email: Christicailsannas@gmail.com
}

DOI: https://doi.org/10.35451/jfm.v1i2.144

\begin{abstract}
The use of traditional medicine is the main choice of society in addition to the inability of people to buy modern medicines, raw materials easily obtained and the price is economical. For example Soursop leaf lately is often used as an alternative treatment is known to contain chemical compounds that are able to treat various diseases. In addition, traditional medicine has relatively small side effects and is relatively safe if used properly and without abuse if the information obtained is quite clear. Therefore researchers are interested to make a quality and nutritious extract so that herbal products maintained quality and quality to achieve it needs to be standardized syrup leaf extract quality According to Materia Medika Indonesia in order to get the extract that is qualified and efficacious.

This study used experimental design including sample preparation, soursop leaf extract, macroscopic examination and simplicia microscopic, phytochemical screening examination, and characteristic examination of soursop leaf extract.

phytochemical screening obtained from ethanol extract of soursop leaf contains alkaloid compounds, flavonoids, saponins, tannins, and steroids / triterpenoids. The filtrate obtained with Rotary Evaporator and viscous extract of $98.532 \mathrm{~g}$ with a thickened viscosity ratio of $6.5688 \%$. The result of characterization of soursop leaf extract of ethanol obtained $2.23 \%$ moisture content, total ash content of $5.60 \%, 1.03 \%$ insoluble ash content, $19.46 \%$ soluble juice content, ethanol soluble concentration 13,38\%. The results of the characterization of soursop leaf extract (Annona muricata Linn.) Meet the requirements in accordance with Materia Medika Quality Strandar Indonesia.
\end{abstract}

Keywords: Soursop leaf, quality, extract, characterization 


\section{PENDAHULUAN}

\section{LatarBelakang}

Indonesia kaya akan sumber bahan obat alam dan tradisional yang secara turun temurun telah digunakan sebagai ramuan obat tradisional. Pengobatan tradisional dengan tanaman obat diharapkan dapan dimanfaatkan dalam pembangunan kesehatan masyarakat (Febriani dkk, 2015).

Tanaman sirsak (Annona muricata Linn.) merupakan salah satu tanaman dari kelas

Dicotyledonae, keluarga,Annonaceaedan genus Annona. Nama sirsak berasal dari bahasa Belanda, yakni Zuurzakyang berarti kantong asam (Zuhud, 2011).

Tumbuhan sirsak dikenal sebagai tanaman buah dengan gizi dan merupakan bahan obat tradisional yang memiliki multikhasiat. Tanaman sirsak banyak digunakan sebagai tanaman obat, karena tanaman ini memiliki khasiat obat dan digunakan sebagai obat dalam penyembuhan maupun pencegahan penyakit (Lesmana, 2017).

Kandungan kimia yang terdapat pada daun sirsak diantarannya adalah alkaloid, flavanoid, karbohidrat, glikosida, saponin, tanin, fitosterol, terfenoid dan protein (Febriani dkk, 2015).

Obat tradisional merupakan bahanbahan obat yang berasal dari alam, baik bersumber dari hewan, mineral ataupun tumbuh-tumbuhan dan Indonesia yang beriklim tropis mempunyai sumber daya hayati yang beraneka ragam serta menghasilkan berbagai senyawa kimia alami, dalam pengobatan tradisional digunakan sebagai ramuan yang berasal dari sumber daya hayati seperti tumbuhan baik berupa akar, kulit batang, kayu, daun, bunga,buah dan biji (Marjoni, 2016).

Penggunaan obat tradisional menjadi pilihan utama masyarakat disamping ketidak mampuan masyarakat membeli obat-obat modern, bahan bakunya mudah diperoleh serta harganya ekonomis. Misalnya Daun sirsak akhir-akhir ini sering digunakan sebagai pengobatan alternatif yang diketahui memiliki kandungan senyawa kimia yang mampu mengobati berbagai penyakit. Selain itu obat tradisional memiliki efek samping yang relatif kecil dan relatif aman jika digunakan secara tepat dan tanpa penyalahgunaan jika diperoleh informasi yang cukup jelas.

Oleh karena itu peneliti tertarik untuk membuat ekstrak yang bermutu dan berkhasiat agar produk-produk herbal terjaga kualitas dan mutunya untuk mencapai hal tersebut perlu dilakukan standarisasi mutu ekstrak daun sirsak Menurut Materia Medika Indonesia terlebih dahulu agar mendapatkan ekstrak yang memang bermutu dan berkhasiat.

\section{METODEPENELITIAN}

\section{Jenis dan Rancangan Penelitian}

Penelitian ini menggunakan rancangan penelitian eksperimental laboratorium terdiri dari beberapa tahapan meliputi: pengumpulan, pembuatan simplisia, identifikasi senyawa metabolit sekunder, skrining fitokimia dan uji mutu simplisia daun sirsak untuk menguji mutu ekstrak daun Sirsak (Annona muricata Linn.)dengan metode maserasi.

\section{Waktu dan Tempat Penelitian}

Pembuatan ekstrak daun sirsak (Annona muricata Linn.)dilakukan di laboratorium Kimia Analisis Fakultas Farmasi Institut Kesehatan Deli Husada. dilakukan selama \pm 2 bulan, terhitung mulai dari bulan Maret tahun 2018 . 


\section{Populasi dan Sampel}

Populasi pada penelitian ini adalah tanaman daun sirsak (AnnonamuricataLinn.)yang tumbuh Di Daerah Sei Jawi-Jawi dan sampel pada penelitian ini adalah ekstrak dari daun sirsak (AnnonamuricataLinn.) dengan dilakukannya skrining fitokimia ekstrak Etanol $70 \%$ daun sirsak (AnnonamuricataLinn.) dan karakterisasi ekstrak etanol $70 \%$ daun sirsak (AnnonamuricataLinn.) sehingga mendapatkan ekstrak yang memang dapat terjaga kualitas, mutu dan khasiatnya yang dapat menyembuhkan berbagai penyakit.

\begin{abstract}
Alat
Alat-alat yang digunakan dalam penelitiaan ini adalah sebagai berikut: Gelas ukur $500 \mathrm{ml}$ (Pyrex), gelas ukur $250 \mathrm{ml}$ (pyrex), gelas ukur $100 \mathrm{ml}$ (Pyrex), erlenmeyer $250 \mathrm{ml}$ (Aprox), erlenmeyer 100 $\mathrm{ml}$ (Aprox), beaker glass $250 \mathrm{ml}$ (Pyrex), beaker glass $100 \mathrm{ml}$ (Pyrex) tabung reaksi (Pyrex), cawan penguap, batang pengaduk, piknometer, timbangan analitik (Kern), alat rotary evaporator (Heidolp), thermometer, corong pisah (Pyrex), kertas saring, pipet tetes, corong (Pyrex), hot plate (Arec), Bola lampupijar 40 Wath (Philips), kardus, Koran, pisauchater, talenan, ember.
\end{abstract}

\section{Bahan}

Bahan yang digunakan dalam penelitian adalah: daun Sirsak (Annona muricata Linn.), etanol 70\%, etanol 95\%, nheksan, asam asesat anhidrat, aquadest, kloroform, tolune, serbuk $\mathrm{MgSO}_{4}, 2 \mathrm{ml}$ amil alkohol, $\mathrm{FeCl}_{3}, \mathrm{H} 2 \mathrm{SO} 4, \mathrm{HCl} 2 \mathrm{~N}, \mathrm{HCl}$ pekat, HCL encer, pereaksi mayer, pereaksi dragendrof, pereaksi bouchat, perekasi molish.

\section{Pembuatan Larutan Pereaksi}

Pembuatan larutan pereaksi meliputi pereaksi molish, asam sulfat $2 \mathrm{~N}$, mayer, dragendorff, bouchardat, timbal (II) asetat 0,4 $\mathrm{M}$, besi (III), klorida $10 \%$, asam nitrat $0,5 \mathrm{~N}$ (Depkes RI, 1995).

\section{Pengambilan Sampel}

Sampel yang digunakan dalam penelitian ini adalah daun sirsak yang diambil dari Jl. Raden Ajeng Kartini, Desa. Sei JawiJawi, Kec. Panai Hulu, Kab. Labuhan Batu, Prov. Sumatera Utara. Pengambilan sampel dilakukan secara purposif tanpa membandingkan dengan sampel yang sama dari daerah lain.

\section{Pembuatan simplisia}

Helaian daun sirsak dibersihkan dari pengotoran dan tulang daunnya dibuang, dicuci dengan air bersih, ditiriskan lalu ditimbang berat basahnya.Selanjutnya dikeringkan di lemari pengering pada suhu \pm $40^{\circ} \mathrm{C}$ hingga rapuh. Sampel yang telah kering diserbuk dengan blender dan disimpan dalam wadah kering tertutup rapat.

\section{Pembuatan Ekstrak}

Serbuk simplisia yang telah kering dimaserasi dimasukkan ke dalam wadah kaca berwarna gelap, lalu ditambahkan pelarut etanol $70 \%$ sampai serbuk simplisia terendam, dibiarkan selama 5 hari sambil sekali-kali diaduk. Pisahkan maserat, ampas dimaserasi kembali dengan pelarut etanol $70 \%$ dengan cara yang sama di atas selama 2 hari, maserat dipisahkan. Semua maserat yang diperoleh digabung, kemudian diuapkan dengan alat rotary evaporator dengan suhu $\pm 40^{\circ} \mathrm{C}$, hasilnya diperoleh ekstrak kental (Hapsari, 2017).

\section{Pemeriksaan Makroskopik}

Pemeriksaan makroskopik dilakukan terhadap simplisia daun sirsak. Pemeriksaaan yang dilakukan meliputi bentuk, rasa, bau, dan warna (Andriani, 2016).

\section{Pemeriksaan Mikroskopik}

Pemeriksaan mikroskopik dilakukan terhadap serbuk simplisia daun sirsak yaitu untuk melihat bagian jaringan yang dimiliki oleh daun sirsak tersebut. Pemeriksaan dilakukan dengan menambahkan larutan kloralhidrat $70 \%$ LP, kemudian diamati dibawah mikroskop (Andriani, 2016).

Pemeriksaan Skrining Fitokimia

Pemeriksaan skrining fitokimia meliputi: uji alkaloid, Flavonoid, Tanin, Saponin, dan Steroida/Triterpenoida, Glikosida sianogenik.

\section{Pemeriksaan Karakterisasi Ekstrak}

Pemeriksaan karakterisasi simplisia meliputi pemeriksaan penetapan kadar air, penetapan kadar sari larut dalam air, penetapan kadar sari larut dalam etanol, penetapan kadar abu total, penetapan kadar abu tidak larut dalam asam. 


\section{HASIL DAN PEMBAHASAAN}

\section{Hasil Pengambilan Daun dan Pengeringan Daun}

Hasil pengambilan daun sirsak (Annona muricata Linn.)yang segar dan
Pemeriksaan

Makroskopik

dipetik langsung dari pohonnnya dengan berat sebanyak $20 \mathrm{~kg}$ yang sudah dipisahkan dari batang. Daun sirsak (Annona muricata Linn.)tersebut dikeringkan dan diperoleh berat sampel kering sebanyak $4 \mathrm{~kg} 8$ Ons dan daun kering diblender menjadi serbuk simplisia dengan berat $2 \mathrm{~kg}$.

Tabel 4.1 hasil pemeriksaan makroskopik daun sirsak

\begin{tabular}{|c|l|l|l|}
\hline No & Organoleptis & \multicolumn{1}{|c|}{ Hasil } & \multicolumn{1}{c|}{ Pustaka } \\
\hline 1 & Bentuk & Elips, bagian ujung daun runcing & Elips \\
\hline 2 & Bau & Beraroma khas & Bau khas \\
\hline 3 & Rasa & Pahit sedikit getir & Pahit \\
\hline 4 & Warna & Hijau muda-tua & $\begin{array}{l}\text { Kehijauan-hijau } \\
\text { kecoklatan }\end{array}$ \\
\hline 5 & Ukuran & $\begin{array}{l}\text { Panjang } 14 \mathrm{~cm} \\
\text { Lebar } \quad 6 \mathrm{~cm}\end{array}$ & $\begin{array}{l}\text { Panjang : 6-18 cm } \\
\text { Lebar }: 2-6 \mathrm{~cm}\end{array}$ \\
\hline
\end{tabular}

\section{*Pustaka Depkes RI 1989.}

\section{Hasil Pemeriksaan Mikroskopik Serbuk} Simplisia

Hasil pemeriksaan mikroskopik terhadap serbuk simplisia daun sirsak. Dari hasil uji diperoleh adanya: Parenkim bernoktah, Epidermis atas, Jaringan palisade, Pembuluh kayu dengan penebalan tangga, Stomata tipe anomositik, Rambut penutup, Serabut.

\section{Hasil Ekstraksi Serbuk Simplisia}

Daun sirsak (Annona muricata

Linn.)sebanyak $1500 \mathrm{~g}$ serbuk, dimaserasi dengan pelarut etanol $70 \%$ sampai serbuk terendap sempurna dan terlindung dari cahaya. Filtrat yang diperoleh kemudian dipekatkan dengan Rotary Evaporator dan diperoleh ekstrak kental sejumlah 98,532 g dengan randemen ekstrak kental sebesar $6,5688 \%$.

Tabel 4.2 Hasil rendemen daun sirsak

\begin{tabular}{|c|c|c|c|c|}
\hline No & Asal Tanaman & $\begin{array}{c}\text { Berat simplisia yang } \\
\text { diekstraksi }\end{array}$ & $\begin{array}{c}\text { Berat ekstrak yang } \\
\text { didapat }\end{array}$ & Rendemen (\%) \\
\hline 1. & Sei jawi-jawi & $1500 \mathrm{~g}$ & $98,532 \mathrm{~g}$ & $6,5688 \%$ \\
\hline
\end{tabular}

\section{Hasil Skrining Fitokimia}

Hasil skrining fitokimia serbuk simplisia dan ekstrak kental daun sirsak diperoleh adanya senyawa golongan alkaloid, flavonoid, saponin, tanin, steroid/Triterpenoida.

Tabel 4.3 Hasil skrining fitokimia ekstrak kental daun Sirsak.

\begin{tabular}{|c|c|c|c|}
\hline \multirow{2}{*}{ No } & Golongan senyawa & \multicolumn{2}{|c|}{ Ekstrak } \\
\cline { 3 - 4 } & Alkaloid & $\sqrt{ }$ & $(-)$ \\
\hline 1. & Flavanoid & $\sqrt{ }$ & - \\
\hline 2. & Tanin & $\sqrt{ }$ & - \\
\hline 3. & Saponin & $\sqrt{ }$ & - \\
\hline 4. &
\end{tabular}

\begin{tabular}{|c|c|c|c|}
\hline 5. & $\begin{array}{c}\text { Steroida/ } \\
\text { Triterpenoid }\end{array}$ & $\sqrt{ }$ & - \\
\hline 6. & $\begin{array}{c}\text { Glikosida } \\
\text { sianogenik }\end{array}$ & - & - \\
\hline
\end{tabular}

Tabel 4.4 Hasil skrining fitokimia serbuk simplisia daun sirsak

\begin{tabular}{|c|c|c|c|}
\hline \multirow{2}{*}{ No } & Golongan senyawa & \multicolumn{2}{|c|}{ Simplisia } \\
\cline { 3 - 4 } & Alkaloid & $(+)$ & $(-)$ \\
\hline 1. & $\sqrt{ }$ & - \\
\hline 2. & Flavanoid & $\sqrt{ }$ & - \\
\hline 3. & Tanin & $\sqrt{ }$ & - \\
\hline 4. & Saponin & $\sqrt{ }$ & - \\
\hline 5. & $\begin{array}{c}\text { Steroida/ } \\
\text { Triterpenoid }\end{array}$ & $\sqrt{ }$ & - \\
\hline
\end{tabular}




\begin{tabular}{|c|c|c|c|}
\hline 6. & $\begin{array}{c}\text { Glikosida } \\
\text { sianogenik }\end{array}$ & - & - \\
\hline
\end{tabular}

Hasil Karakterisasi Simplisia
Karakterisasi simplisia meliputi penetapan kadar air, kadar abu total, kadar abu tidak larut dalam asam, kadar sari larut air, kadar sari larut etanol dilakukan dengan tujuan untuk menjamin keseragaman mutu simplisia agar memenuh persyaratan standar simplisia dan ekstrak.

Tabel 4.2Hasil karakterisasi serbuk daun sirsak

\begin{tabular}{|c|l|l|l|}
\hline No & \multicolumn{1}{|c|}{ Penetapan karakterisasi } & Hasil & \multicolumn{1}{|c|}{ Persyaratan MMI } \\
\hline 1. & Kadar air & $2,23 \%$ & Tidak lebih dari $10 \%$ \\
\hline 2. & Kadar abu & $5,60 \%$ & Tidak lebih dari $6 \%$ \\
\hline 3. & Kadar abu tidak larut dalam asam & $1,03 \%$ & Tidak lebih dari $1,5 \%$ \\
\hline 4. & Kadar sari yang larut dalam air & $19,46 \%$ & Tidak kurang dari $18 \%$ \\
\hline 5. & Kadar sari yang larut dalam etanol & $13,38 \%$ & Tidak kurang dari 12,5 \\
\hline
\end{tabular}

\section{Pustaka Depkes RI 1989.}

\section{KESIMPULAN DAN SARAN}

\section{Kesimpulan}

Hasil karakterisasi ekstrak daun sirsak (Annona muricata Linn.) yaitu kadar air $2,23 \%$, kadar sari yang larut dalam air $19,46 \%$, kadar sari yang larut dalam etanol $13,38 \%$, kadar abu total 5,60\%, kadar abu tidak larut asam $1,03 \%$. Hasil karakteristik simplisia daun sirsak yang terdapat pada buku MMI edisi IV, kadar yang diperoleh dari hasil karakteristik simplisa daun sirsak tersebut memenuhi syarat yang sesuai dengan standart simplisia daun sirsak pada monografi buku Materia Medika Indonesia.

Hasil pemeriksaan skrining fitokimia terhadap serbuk simplisia menunjukkan adanya senyawa alkaloid, flavonoid, tanin, saponin, dan triterpenoid/steroid. Sedangkan hasil pemeriksaan mikroskopik terhadap serbuk simplisia menunjukkan adanya Parenkim bernoktah, Epidermis atas, Jaringan palisade, Pembuluh kayu dengan penebalan tangga, Stomata tipe anomositik, Rambut penutup, Serabut.

Hasil persen rendemen ekstraksi serbuk simplisia secara maserasi dengan pelarut etanol $70 \%$ dari $1500 \mathrm{~g}$ serbuk simplisia setelah diuapkan dengan alat Rotary evaporator diperoleh ekstrak kental sebanyak 98,532 g dengan rendemen sekitar 6,5688 \%.

\section{DAFTAR PUSTAKA}

Andriani. Y.Y., Rahmiyani. I., Amin. S., Lestari. T. (2016). Kadar Fenol Total Ekstrak Daun Dan Buah Biji Pepaya (Carica papaya L.)
Menggunakan Metode Spektrofotometri Uv-vis. Tasikmalaya: STIKes Bakti Tunas Husada Tasikmalaya. Jurnal Kesehatan Bakti Tunas Husada Vol 15, No.1, Hal: 1-6.

Depkes, RI. (1989). Materi Medika Indonesia. Jilid V-VI. Jakarta: Departemen Kesehatan Republik Indonesia. Hal: 537, 538, 541.

Depkes, RI. (1995). Materi Medika Indonesia. Jilid V-VI. Jakarta: Departemen Kesehatan Republik Indonesia. Hal: 537, 538, 541.

Febriani, D., Mulyanti, D., Riamawati, E. (2015). Karakterisasi Simplisia Dan Ekstrak Etanol Daun Sirsak (Annona muricata Linn). Bandung: Fakultas MIPA, Unisba. Bandung. ISSN 2460-6472.

Hansel, H., Pinanddjojo, D., Tih, F. (2013). Pengaruh Teh Daun Sirsak (Annona muricata Linn.) Terhadap Penurunan Tekanan Darah Normal Pada Laki-Laki Dewasa Muda. Bandung: Jurnal Ilmiah Universitas Kristen Maranatha. Hal: 50.

Hapsari,S.W., Rohmayanti.,Fitriana.Y., Missya,P.K.P.(2017).SkriningFito kimiaEkstrakEtanolHerbaPegaga ndanAnalisaRendemen. Magelang : Jurnal Farmasi Universitas Muhammadiyah.

Harbone, J. B. (1987). MetodeFitokimia. Bandung:

Penerbit ITB. Hal: 102, 147, 234, 245

Lesmana, W. A. ( 2017). Uji Ekstrak Daun Sirsak (Annona muricata Linn) 
Pada Caplak (Boophilus

microplus) Berdasarkan Waktu Kematian (In Vitro). Makasar: Skripsi Universitas Hasanuddin. Hal: 1-45.

Marjoni, M. R. (2016). Dasar-Dasar Fitokimia Untuk Diploma III Farmasi. Jakarta: Penerbit Buku Trans Info Media. Hal: 15-16.

Zuhud, E. AM. (2011). Bukti Kedahsyatan Sirsak Menumpas Kanker. Jakarta: PT Agro Media Pustaka. Hal: 2-3, 45.

Zulharmita., Kaspiyah, U., Rivai, H. (2012). Pembuatan dan Karakterisasi Ekstrak Kering Daun Jambu Biji (Psisium guajava L.) Jurnal Farmasi Higea. Vol. 4. No.2. Hal:147-157. 